\title{
Analisis Pengaruh Revitalisasi Design Konstruksi Pasar Tradisional Terhadap Peningkatan Ekonomi Kerakyatan (Studi Kasus Pasar Kepuh Sukoharjo)
}

\author{
Agus Rianto ${ }^{1)}$ \\ 1) Fakultas Teknik, Program Studi Teknik Sipil, Universitas Veteran Bangun Nusantara, Sukoharjo, Jl. \\ Letjen Sudjono Humardhani, No.1, Jombor, Sukoharjo; Telp. 0271-593156. Email: \\ magusrianto123@gmail.com
}

\begin{abstract}
Abstrak
Perkembangan kota-kota besar saat ini lebih bertumpu pada sektor industri, perdagangan dan jasa. Perkembangan kota tersebut investor berlomba-lomba untuk berinvestasi dalam hal bangunan komersial. Maraknya bangunan komersil modern yang sedang ramai peminatnya saat ini dan pandangan orang-orang terhadap pasar tradisional hanyalah sebuah tempat berjualan yang tidak jauh dari kekumuhan, membuat pasar tradisional semakin hari semakin berkurang peminatnya. Kondisi pasar kepuh sukoharjo yang masih kurang nyaman untuk berjualan dan berbelanja, dikarenakan area bagian dalam pasar mempunyai suasana sumpek diakibatkan oleh layout ruang pasar yang kurang tertata. Hal ini disebabkan masih banyaknya pedagang yang berjualan di luar area pasar. Pintu utama yang kurang menarik, sirkulasi pasar yang kurang tertata dengan baik, penghawaan dan pencahayaan yang belum berfungsi dengan optimal menjadi faktor dari ketidaknyamanan pada pasar. Untuk itu pasar kepuh sokoharjo direvitalisasi desain untuk bisa bersaing dengan pasar-pasar moderen lainya dan untuk peningkatan ekonomi kerakyatan. penerapan pada rancangan bangunan akan menata ulang layout ruang, sirkulasi dan penerapan cross ventilasi, juga penerapan skylight guna memasukan pencahayaan alami untuk ruang dalam pasar. Pelaksanaan program pengembangan pasar tradisional yang dilakukan Pemerintah Sukoharjo dalam rangka meningkatkan ekonomi kerakyatan melalui revitalisasi pasar tradisional bertujuan meningkatkan daya saing pasar dan mengaktifkan kembali kegiatan pasar tradisional agar dapat bersaing dengan pasar modern sehingga bukan hanya meningkatkan pendapatan pedagang tapi juga meningkatkan daya saing untuk memperluas pangsa pasar, dan tujuan akhir dari program tersebut adalah mencapai kesejahteraan pedagang. Revitalisasi tersebut menghasilkan empat aspek diantaranya aspek sosial, aspek non fisik, aspek ekonomi dan aspek fisik. Berdasarkan hasil kuisioner yang telah dibagiakan kepada 50 responden pedagang, sebanyak 80\% responden menyatakan paska revitalisaisi desain konstruksi di pasar kepuh sukoharjo pendapatan ekonomi mengalami peningkatan pendapatan ratta-rata $20 \%$.
\end{abstract}

Kata kunci: redisain, peningkatan ekonomi.

\begin{abstract}
The development of big cities currently relies more on the industrial, trade, and service sectors. As the city develops, investors are competing to invest in commercial buildings. The rise of modern commercial buildings that are currently in high demand and people's views on traditional markets are just places to sell that are not far from a slum, making traditional markets less and less in demand. Sukoharjo Kepuh market conditions are still not comfortable for selling and shopping, because the inner area of the market has a crowded atmosphere due to the unorganized layout of the market space. This is because there are still many traders who sell outside the market area. The main door is less attractive, market circulation is not well organized, ventilation and lighting that is not yet functioning optimally are factors of the inconvenience of the market. For this reason, the Kepuh Sokoharjo market is designed to be revitalized to be able to compete with other modern markets and to improve the people's economy. application to the building design will rearrange the space layout, circulation, and application of crossventilation, as well as the application of skylights to include natural lighting for spaces in the market. The implementation of the traditional market development program carried out by the Sukoharjo Government to improve the people's economy through the revitalization of traditional markets aims to increase market competitiveness and reactivate traditional market activities to compete with modern markets so as not only to increase traders' income but also increase competitiveness to expand market share, and the ultimate goal of the program is to achieve the welfare of traders. The revitalization produces four aspects including social aspects, non-physical aspects, economic aspects, and physical aspects. Based on the results of questionnaires that have been distributed to 50 merchant respondents, as many as $80 \%$ of respondents stated that after the revitalization of the construction design in the Sukoharjo Kepuh market, economic income had increased on average by $20 \%$.
\end{abstract}

Keywords: redesign, increase the economy. 


\section{PENDAHULUAN}

\section{Latar Belakang}

Pasar adalah area tempat jual beli barang dengan jumlah penjual lebih dari satu baik yang disebut sebagai pusat perbelanjaan, pasar tradisional,pertokoan, mall, plasa, pusat perdagangan maupun sebutan lainnya (Peraturan Menteri Perdagangan Republik Indonesia Nomor : 53/M-DAG/PER/12/2008).

Pasar tradisional merupakan tempat bertemunya penjual dan pembeli ditandai dengan adanya transaksi atau tawar menawar antara si penjual dan pembeli secara langsung (Eka, 2015). Menurut Peraturan Daerah Kota Yogyakarta Nomor 2 Tahun 2009 tentang pasar menyatakan bahwa pasar tradisional adalah lahan dengan batas-batas tertentu yang ditetapkan oleh Walikota dengan atau tanpa bangunan yang dipergunakan untuk tempat berjual beli barang dan atau jasa yang meliputi kios, los dan lapak. Pasar tradisional dibagi menjadi 4 tipe yaitu tipe $A$, tipe $B$, tipe $C$, dan tipe D (Peraturan Menteri Perdagangan RI NOMOR 37/M-DAG/PER/5/2017).

Menurut Marlina (2008), pola kegiatan pengguna pasar tradisional yang berbeda tergantung pada kelas ekonomi sosial yang ada, latar budaya setempat, usia dan tujuan kedatangannya. Pengembangan pasar memang tidaklah mudah. Revitalisasi pasar memakan biaya yang tinggi.Selain itu di beberapa tempat pengembangan pasar sering dianggap memarginalisasi pedagang lama karena pedagang ditarik retribusi yang lebih besar. Akibatnya bukan peningkatan kesejahteraan yang didapat, bahkan beberapa pedagang lama tersingkir karena tidak sanggup membayar retribusi. Dengan demikian kebijakan ini harusnya mendapat perhatian lebih supaya dapat membuahkan hasil yang maksimal.

Tujuan utama kebijakan setiap Negara yang sedang membangun diarahkan untuk mencapai kemakmuran dan kesejahteraan bagi seluruh rakyatnya. Untuk mencapai tujuan pembangunan nasional maka pemerintah membangun berbagai sarana dan prasarana. Menurut ketetapan Peraturan Menteri untuk lorong koridor sudah di tetapkan bawasanya ukuran koridor minimum memiliki ukuran 1,5 meter untuk mewadahi pola gerak sirkulasi pada pasar. Pengaturan dimensi koridor di pasar juga terdapat di teori retail spaces oleh Chiara (1992).

Sesuai dengan RENSTRA (Rencana Strategi) dan tahapan pembangunan Kabupaten Sukoharjo, Pemerintah Daerah Kabupaten Sukoharjo mengadakan pembangunan dan perubahan pada beberapa fasilitas umum yang ada di Kabupaten Sukoharjo. Salah satunya adalah pelaksanaan revitalisasi Design Pasar Kepuh Sukoharjo yang membawa dampak pada kepuasan bagi para pedagang yang berjualan di Pasar Kepuh Sukoharjo.

Pasar Kepuh Sukoharjo terletak pada posisi yang strategis yaitu di pinggir jalan utama penghubung antara kota Sukoharjo dengan Wonogiri. Akses yang mudah dijangkau menjadikan Pasar Kepuh Sukoharjo menjadi sasaran pembeli yang akan berbelanja dipasar tersebut.

Posisi yang dekat dengan pusat kota yaitu Sukoharjo menjadikan Pasar Kepuh Sukoharjo jarang sepi dari pengunjung, terutama warga Sukoharjo dan khususnya warga Kepuh itu sendiri. Pelaksanaan revitalisasi design pasar tradisional merupakan usaha pemerintah agar pasar tradisional mampu bersaing dengan pasar modern.

Pembangunan suatu pasar perlu memperhatikan kesejahteraan pedagang maupun pembeli di pasar tersebut. Lewat penataan kembali pasar tradisional yang memperhatikan aspek kenyamanan, pelayanan dan keamanan, maka potensi yang dimiliki pasar tradisional akan dapat meningkat secara ekonomi.

Adapun tujuan dan pembahasan dari penelitian ini adalah untuk mengetahui pengaruh desain pengembangan pasar tradisional di Pasar Kepuh Sukoharjo serta mengetahui peningkatan ekonomi yang terjadi di Pasar Kepuh Sukoharjo.

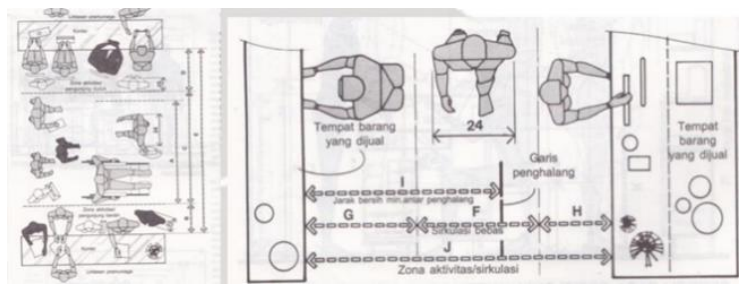

Gambar 1. Antropometrik Lebar Lintas Publik Utama dan Kedua

Sumber: Panero, 1992

\section{METODE}




\section{Metode penelitian}

Dalam hal ini peneliti melakukan beberapa teknis analisis data, yang pertama analisis sebelum di lapangan. Analisis dilakukan terhadap data hasil studi pendahuluan, atau data sekunder yang akan digunakan dalam penulisan. Dalam hal ini data sekunder yang digunakan dalam penulisan ini adalah dengan melakukan observasi, wawancara, dokumentasi dan triangulasi. Sehingga dalam menganalisis data sebelum di lapangan didasarkan pada halhal tersebut. Selanjutnya analisis data di lapangan, dalam analisis data di lapangan peneliti menggunakan model Miles dan Huberman. Yang mana Miles dan Huberman mengungkapkan bahwa analisis data kualitatif dilakukan secara interaktif dan berlangsung secara terus-menerus sehingga datanya sudah jenuh.

Dalam hal ini meliputi tiga proses yaitu:

a. Reduksi Data

Yaitu merangkum, memilih hal-hal yang pokok, memfokuskan pada hal-hal yang penting, dicari tema dan polanya dan membuang yang tidak perlu.

b. Penyajian Data

Penyajian data ini dapat dilakukan dengan bentuk tabel, grafik, dan sejenisnya. Dan dalam penulisan ini peneliti lebih memfokuskan penyajian data dengan menggunakan teks yang bersifat naratif.

c. Verifikasi

Kesimpulan awal yang dikemukakan pada tahap awal masih bersifat sementara, dan akan berubah bila tidak ditemukan buktibukti yang kuat yang mendukung pada tahap pengumpulan data berikutnya.

\section{HASIL DAN PEMBAHASAN}

Berdasarkan hasil kuisioner yang telah dibagiakan kepada 50 responden pedagang, sebanyak $80 \%$ responden menyatakan paska revitalisaisi desain kontruksi di pasar kepuh sukoharjo pendapatan ekonomi mengalami peningkatan. Menurut beberapa pedagang yang berdagang mereka setelak pelaksanaan progam revitalisaisi desain kontruksi di pasar kepuh sukoharjo mengalami peningkatan hingga 50\%. Pun kuisioner yang telah dibagiakan kepada 20 responden pengunjung, sebanyak $90 \%$ responden menyatakan paska revitalisaisi desain kontruksi di pasar kepuh sukoharjo mereka akan kembali karena desain yang di hadirkan di pasar kepuh sukoharjo lebih moderen dari sebelumnaya. Dari 100\% responden pedagang hanya $14 \%$ yang menyatakan pendapatan setelah revitalisaisi desain kontruksi di pasar kepuh sukoharjo tidak mengalami peningkatan ,ini akibat tempat dagang yang dulu berada di tempat yang strategis menjadi tempat yang kurang strategis.

Hal ini selaras dengan pedagang lain yang menyatakan bahwa setelah pelaksanaan revitalisaisi desain kontruksi di pasar kepuh sukoharjo bertambahnya pengunjung 50\% akibat menurut asumsi pedagang, pengunjung tersebut ingin merasakan suasana baru di pasar kepuh sukoharjo. Dari aspek kualitas desain kontruksi bangunan, telihat lebih baik karena desian yang lebih moderen. Dipasar kepuh juga di lengkapi petugas pembersih yang bertugas membersihkan baguanan agar terlihat kerapian kan kenyamanan pengunjung.

Berdasarkan 6\% responden pedagang mengatakan bahwa pendapatan mereka dari sebelum dan sesudah pelaksanaan revitalisaisi desain kontruksi di pasar kepuh sukoharjo sama saja tidak ada perubahan. Ada atau tidak adanya progam revitalisaisi desain kontruksi di pasar kepuh sukoharjo tidak mengubah pendapatan.

\section{Peningkatan Ekonomi Kerakyatan Untuk Pedagang Setelah Revitalisasi Pasar Kepuh Sukoharjo}

Berdasarkan observasi yang dilakaukan, pelaksanaan revitalisasi desain kontruksi di Pasar Kepuh Sukoharjo sesungguhnya memiliki pengaruh positif untuk aspek fisik bangunan karena menjadi lebih baik atau pun lebih modern . lebih dari itu pelaksanaan revitalisaisi desain kontruksi di Pasar Kepuh Sukoharjo juga dapat meningkatkan pendapatan ekonomi yaitu sebesar rata-rata $20 \%$,dengan pengolahan menejemen yang baik dalam rangka untuk pemeliharaan sarana dan prasarana untuk membuat para pengunjung betah dankembali lagi berbelanja di pasar kepuh tersebut, untuk dapat meningkatkan ekonomi kerakyatan yang dimaksud. Dan juga pengawasan yang ketat agar pedagang mengikuti prosedur yang berlaku.

\section{SIMPULAN}

Berdasarkan data yang berhasil dikumpulkan dan analisis yang telah dilakukan tentang revitalisaisi desain kontruksi di pasar kepuh 
sukoharjo dalam meningkatkan Pendapatan Ekonomi Kerakyataaan di Pasar Kepuh Sukoharjo, maka dapat ditarik kesimpulan bahwa pelaksanaan program pengembangan pasar tradisional yang dilakukan Pemerintah Sukoharjo dalam rangka meningkatkan ekonomi kerakyatan melalui revitalisasi pasar tradisional bertujuan meningkatkan daya saing pasar dan mengaktifkan kembali kegiatan pasar tradisional agar dapat bersaing dengan pasar modern sehingga bukan hanya meningkatkan pendapatan pedagang tapi juga meningkatkan daya saing untuk memperluas pangsa pasar, dan tujuan akhir dari program tersebut adalah mencapai kesejahteraan pedagang. Revitalisasi tersebut menghasilkan empat aspek diantaranya aspek sosial, aspek non fisik, aspek ekonomi dan aspek fisik. Berdasarkan hasil kuisioner yang telah dibagiakan kepada 50 responden pedagang, sebanyak $80 \%$ responden menyatakan paska revitalisaisi desain kontruksi di pasar kepuh sukoharjo pendapatan ekonomi mengalami peningkatan pendapatan rata-rata $20 \%$.

\section{DAFTAR PUSTAKA}

Chira. 1992. Time Saver Standards for Interior Design and Space Planning. New York: Mc Graw Hill Book Company.

Eka. 2015. Pengaruh Keberadaan Pasar Tradisional Terhadap Kesejahteraan Pedagang Dampaknya Pada Retribusi Pasar.

Marlina, Endy. 2008. Panduan Perancangan Bangunan Komersial. Andi Offset: Yogyakarta.

Peraturan Daerah Kota Yogyakarta Nomor 2. 2009. Pasar. Lembaran Daerah Kota Yogyakarta Tahun 2009 Nomor 25.

Panero, Julius. 2003. Dimensi Manusia dan Ruang Interior. Jakarta: Erlangga.

Peraturan Menteri Perdagangan Nomor 53/MDag/Per/12/2008. 2008. Pedoman Penataan Dan Pembinaan Pasar Tradisional, Pusat Perbelanjaan, dan Toko Modern.

Republik Indonesia. 2017. Peraturan Menteri Perdagangan Republik Indonesia Nomor 37/M-Dag/Per/5/2017 tentang Pedoman Pembangunan dan Pengelolaan Sarana Perdagangan. 